\title{
KRAS testing and first-line treatment among patients diagnosed with metastatic colorectal cancer using population data from ten National Program of Cancer Registries in the United States
}

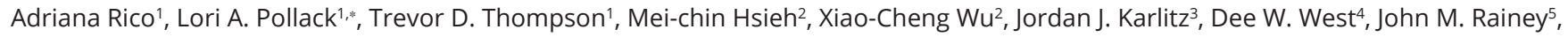
Vivien W. Chen ${ }^{2}$ on behalf of the Enhancement of NPCR for Comparative Effectiveness Research team ${ }^{6}$

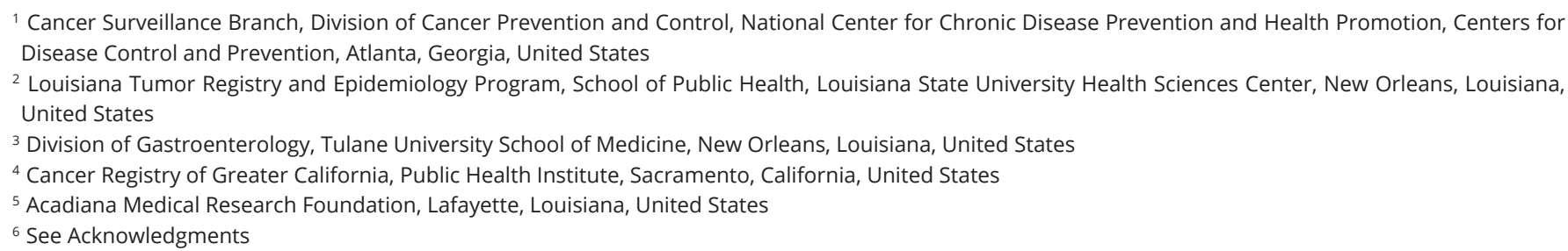

\begin{abstract}
Background: In 2011, the National Comprehensive Cancer Network (NCCN) recommended KRAS testing for metastatic colorectal cancer (mCRC) patients. Our study assessed KRAS testing prevalence and its association with socio-demographic and clinical factors and examined first-line treatment. Methods: Ten state population-based registries supported by Centers for Disease Control and Prevention's (CDC) National Program of Cancer Registries (NPCR) collected detailed cancer information on mCRC cases diagnosed in 2011, including KRAS biomarker testing and first-line treatment from ten central cancer registries. Data were analyzed with Chi-square tests and multivariate logistic regression. Results: Of the 3,608 mCRC cases, $27 \%(n=992)$ had a documented KRAS test. Increased age at diagnosis $(p<0.0001)$, racial/ethnic minorities $(p=0.0155)$, public insurance $(p=0.0018)$, and lower census tract education $(p=0.0023)$ were associated with less KRAS testing. Significant geographic variation in KRAS testing $(p<0.0001)$ ranged from $46 \%$ in New Hampshire to $18 \%$ in California. After adjusting for all covariates, age and residence at diagnosis (both $\mathrm{p}<0.0001$ ) remained predictors of KRAS testing. Non-Hispanic Blacks had less KRAS testing than non-Hispanic Whites ( $O R=0.77,95 \% \mathrm{Cl}=0.61-0.97)$. Among those tested and found to have normal (wild-type) $K R A S, 7 \%$ received anti-EGFR treatment; none received such treatment among those with KRAS mutated gene. Conclusions: Despite NCCN guideline recommendations, 73\% of mCRC cases diagnosed in 2011 had no documented KRAS test. Disparities in KRAS testing existed based on age, race, and residence at diagnosis. Impact: These findings show the capacity of monitoring KRAS testing in the US using cancer registry data and suggest the need to understand the low uptake of KRAS testing, and associated treatment choices during the first year since diagnosis.
\end{abstract}

Keywords: KRAS testing; colorectal cancer; NPCR registries

\section{Introduction}

Although the incidence of colorectal cancer (CRC) has declined over the years, from 57.6 cases in 1998 to 38.9 cases in 2012 per 100,000 population, CRC remains the second leading cause of cancer deaths among men and women of all races in the United States [1]. In 2015, the United States Cancer Statistics reported there were 51,516 CRC deaths in 2012 among men and women of all races [1]. Metastatic colorectal cancer (mCRC), defined as stage IV, accounts for about $20 \%$ of newly diagnosed CRC and has a five year relative survival rate of $14 \%$ [2].

Studies indicate that mutations in the Kirsten rat sarcoma viral oncogene homolog (KRAS) occur in approximately
* Corresponding author: Lori A. Pollack, MD, MPH, Centers for Disease Control and Prevention, 4770 Buford Hwy., MS F-76. Atlanta, GA 30341. 3717, United States. Tel.: 770-488-5045; Fax: 770-488-4759; Email: lop5@ cdc.gov

Received 23 September 2016 Revised 15 January 2017 Accepted 24 January 2017 Published 30 January 2017

Citation: Rico A, Pollack LA, Thompson TD, Hsieh MC, Wu XC, Karlitz J, West DW, Rainey JM, Chen VW, on behalf of the Enhancement of NPCR for Comparative Effectiveness Research team. KRAS testing and first-line treatment among patients diagnosed with metastatic colorectal cancer using population data from ten National Program of Cancer Registries in the United States. J Cancer Res Ther. 2017; 5(2):7-13. DOI: 10.14312/20524994.2017-2

Copyright: () 2017 Rico A, et al. Published by NobleResearch Publishers. This is an open-access article distributed under the terms of the Creative Commons Attribution License, which permits unrestricted use, distribution and reproduction in any medium, provided the original author and source are credited. 
$35 \%$ to $43 \%$ of mCRC [3-6]. Results from clinical trials showed that patients with the normal (wild-type) KRAS gene responded to anti-epidermal growth factor receptor (EGFR) monoclonal antibody therapies, cetuximab $\left(\right.$ Erbitux $\left.^{\circledR}\right)$ and panitumumab (Vectibix $\left.{ }^{\circledR}\right)$; whereas those with the KRAS mutation did not [6-8]. Furthermore, these monoclonal antibody therapies have demonstrated improved progression-free survival and overall survival in patients with wild-type KRAS tumors $[9,10]$. As a result, the National Comprehensive Cancer Network (NCCN) updated its CRC guidelines in 2008 to recommend KRAS testing for all $\mathrm{mCRC}$ patients upon diagnosis and prior to treatment [11]. In April 2009, the American Society of Clinical Oncology (ASCO) released a guideline recommendation to test for KRAS in $\mathrm{mCRC}$ patients who were candidates for anti-EGFR treatment [12]. Consequently, the US Food and Drug Administration (FDA) implemented labeling changes in July 2009 to cetuximab (originally approved in 2004) and panitumumab (originally approved in 2006) after clinical trials revealed the benefit of these agents for those with a wild-type KRAS oncogene [13]. At the time of data collection for mCRC diagnosis year 2011, NCCN guidelines recommended testing for the KRAS oncogene only among mCRC patients [14]. However, the evolution of recent research found that $\mathrm{MCRC}$ patients with RAS mutations on the KRAS as well as the NRAS oncogene do not respond to anti-EGFR treatment either [15-17]. NCCN currently recommends genotyping tumor tissue for both KRAS and NRAS mutations for $\mathrm{mCRC}$ giving a result of either normal (wild-type) and able to receive anti-EGFR treatment; or a mutated status and should not be treated with antiEGFR treatment [18]. NCCN recommends genotyping the tumor tissue to test for these oncogenes; however, a particular method (e.g., sequencing, hybridization) is not recommended [18].

The primary objective of this study was to determine KRAS testing in clinical practice for MCRC diagnosis year 2011 in ten US states using data from the Centers for Disease Control and Prevention's (CDC) population-based central cancer registries as well as evaluate the association of patient demographics and socioeconomic measures with the use of KRAS testing. This study also examines treatment received within 12 months of diagnosis of $\mathrm{mCRC}$, with attention to anti-EGFR treatment by KRAS testing status and results.

\section{Materials and methods}

\section{Data source}

Funding from the American Recovery and Reinvestment Act of 2009 allowed CDC's National Program of Cancer Registries (NPCR) to enhance standard practices and collect additional biomarker and treatment data in ten central cancer registries (Alaska, California, Colorado, Florida, Idaho, Louisiana, New Hampshire, North Carolina, Rhode Island, and Texas) to support Comparative Effectiveness Research (CER) [19]. Participating central cancer registries collected data on all patients who were diagnosed with CRC in 2011 in their entire state with the exception of California and Florida, whose catchment areas were 13 counties in the Sacramento area and 5 Miami metro counties, respectively. At the time of data collection for diagnosis year 2011, the NCCN guidelines recommended testing for the KRAS oncogene only [14]. Certified Tumor Registrars abstracted both NPCR required standard variables from the North American Association of Central Cancer Registries (NAACCR) and defined non-NAACCR standard data items and included information up to 12 months post-diagnosis [19].

Information regarding KRAS biomarker testing and firstline chemotherapy agents was collected for the first time in NPCR as part of this project. Abstractors collected KRAS testing and treatment information by several means including onsite visits to diagnosis/treatment facilities, remote access to patients' medical records, or by facilities sending the information to the registries [19]. Receiving a KRAS test, defined as "Tested" meant there was documentation in a patient's medical record; otherwise, if no documentation was found then we assumed no KRAS testing was performed and defined as "Not Tested." To standardize collection of treatment agents, abstractors collected the Cancer Chemotherapy National Service Center (NSC) number assigned to oncology drugs provided by the National Cancer Institute (NCI) SEER*Rx - Interactive Antineoplastic Drugs Database [20], or if a number did not exist in the database CDC assigned the drug a specific number. During the creation of the analytic data set, project staff converted NSC numbers to generic agent names using information provided by NCl's SEER $* \mathrm{Rx}$ - Interactive Antineoplastic Drugs Database and SAS programs. A detailed description of the CER project and study methodology has been published [19]. Currently, NPCR does not collect KRAS or NRAS biomarker testing data; the collection of KRAS biomarker data was a special project from cancer diagnosis year 2011 only.

\section{Study population}

This study included 4,626 male and female patients residing in ten CDC central cancer registries who were diagnosed with mCRC (ICD-O-3 site codes: C18.0, C18.2 - C18.9, C19.9, and C20.9) in 2011. We excluded cases with histologies that did not meet the American Joint Committee on Cancer (AJCC) $7^{\text {th }}$ edition staging for CRCS $(\mathrm{n}=93)$, missing KRAS testing information $(n=6)$, unknown/other race $(n=147)$, transsexual/unknown sex $(n=3)$, and patients who died within two months of diagnosis or had missing information on the time from diagnosis to death $(n=769)$. These patients were excluded because if they were too sick to be treated then more than likely they would not be tested for KRAS. A total of 3,608 (78\%) mCRC cases met criteria and were included in the data analysis (Figure 1).

\section{Data variables}

Demographic variables evaluated were age at diagnosis, race/ethnicity, sex, residence at diagnosis, and insurance status. Census tract-level socioeconomic variables assessed were poverty level, education, and rural/urban residence, which were linked to the data set from the 2010 US Census Bureau American Community Survey (ACS) [21]. Poverty level was dichotomized into two categories: living in a census tract with $<20 \%$ or $\geq 20 \%$ of people living under federal poverty level. Education level was also dichotomized into two categories: low and high education 
Figure 1. KRAS testing and result among Stage IV colorectal cancer diagnosed in 2011.
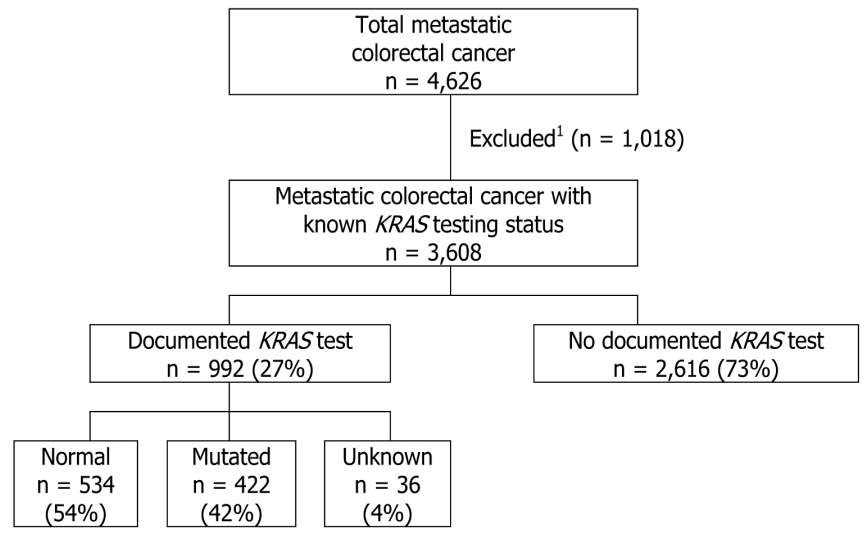

Note: ${ }^{1}$ Time to death within two months or missing ( $\left.n=769\right)$, unknown race or sex $(n=150)$, histology that did not meet criteria for staging $(n=93)$, missing KRAS testing information $(\mathrm{n}=6)$.

level. Low education level was defined as living in a census tract with $\geq 25 \%$ adults (age 25 years and older) without a high school education, and high education level was defined as living in a census tract with $<25 \%$ without a high school education. Rural/urban residence was defined as urban, rural, or mixed by census tract. A comorbid condition was defined as a pre-existing health condition and/or a health condition diagnosed during the cancer treatment. Quan's coding algorithms were used to define comorbid conditions in ICD-9-CM [22]. We included up to 15 comorbidities in this study, and they were categorized based on the number of Charlson comorbidities (none, 1, 2 or more) [23]. Comorbidities were considered not present if no comorbidity was documented in the medical chart or if it was unknown whether a patient had Charlson comorbidity when the cancer was diagnosed. Treatment regimens were then defined according to 2011 NCCN guidelines [14]. Receiving anti-EGFR treatment was defined as receiving cetuximab or panitumumab, either in combination with a regimen or alone.

\section{Statistical methods}

We examined the association of demographics, socioeconomic measures, and comorbidities using the Pearson Chi-square test for discrete variables and the Kruskal-Wallis test for continuous variables; differences were considered significant at $P<0.05$. Some variables had missing information: insurance status $(n=161)$, census tract poverty ( $n=21)$, census tract education ( $n=17)$, and census tract rural/urban $(n=17)$. A multivariate logistic regression model was used to determine the significant predictors of KRAS testing (Tested vs. Not Tested). Independent variables were age at diagnosis, race/ethnicity, sex, residence at diagnosis, insurance status, comorbidities, and census tract-level poverty, education, and rural/urban residence. The linearity assumption for the continuous age variable was assessed using restricted cubic spline functions [24]. The plot of the restricted cubic spline fit suggested a piecewise linear relationship between age at diagnosis and KRAS testing. In the final model, age at diagnosis is transformed using a linear spline function with a knot at age 70 because age was split into two linear segments at age 70 .

\section{Results}

\section{KRAS testing}

Of the 3,608 mCRC cases, 992 (27\%) received a documented KRAS test compared to 2,616 (73\%) with no documented KRAS test (Table 1). Of the 992 cases with a documented KRAS test, 534 (54\%) had a normal KRAS gene, 422 (42\%) had a mutated gene, and $36(4 \%)$ had a test ordered but results were not available in the chart (Figure 1).

Among the patient characteristics (Table 1), older age at diagnosis, race/ethnicity other than White, public insurance, and lower census tract education were all associated with less KRAS testing. Cases who did not receive a KRAS test had a median age of 64 years $\left(\left(25^{\text {th }}, 75^{\text {th }}\right.\right.$ percentile $\left.) 55,75\right)$ compared to a median age of 61 years $(51,69)$ for those who did receive a KRAS test. Among the age categories analyzed, those who were $\geq 75$ had the lowest use of KRAS testing (18\%) compared with the other age groups. Hispanics and non-Hispanic Blacks had the lowest use of KRAS testing ( $25 \%$ and $24 \%$ respectively) compared to nonHispanic Whites (29\%). Those with Medicaid or Medicare and other public insurance had lower use of KRAS testing (26\% and $25 \%$, respectively) compared to those with no insurance and private insurance (both 31\%). Living in a census tract with low education level was associated with lower use of KRAS testing (24\%). There were also significant differences in KRAS testing by residence at diagnosis $(p<0.0001)$. The lowest rates were in California (18\%), Louisiana (23\%), Texas (23\%), and Florida (26\%) among the ten central cancer registries. There were no statistically significant differences in KRAS testing by sex, census tract poverty, census tract rural/urban, and comorbidities.

In multivariate analysis (Table 2), after adjusting for all covariates age at diagnosis, and residence at diagnosis remained significant predictors of KRAS testing (both $\mathrm{p}<$ $0.0001)$. The relationship between age and KRAS testing was non-linear. Increased age was associated with lower KRAS testing, but this effect was stronger above age 70 $(\mathrm{OR}=0.76,95 \% \mathrm{Cl}=0.69-0.84$ vs. $\mathrm{OR}=0.92,95 \% \mathrm{Cl}=$ 0.88 - 0.96 below age 70 per 5-year increase). The model confirmed geographic differences in KRAS testing $(\mathrm{p}<$ 0.0001). Colorado, Idaho, New Hampshire, Rhode Island, and North Carolina had more KRAS testing compared to Texas (referent group). Texas was used as the referent group because they had the largest number of cases. Among these states, the odds of receiving a KRAS test was highest for New Hampshire and Rhode Island (almost 3 times higher). The overall effect of race/ethnicity across all age groups was not statistically significant. However, the effect of non-Hispanic Blacks compared to non-Hispanic Whites was statistically significant; non-Hispanic Blacks had lower KRAS testing compared to non-Hispanic Whites $(\mathrm{OR}=0.77,95 \% \mathrm{Cl}=0.61-0.97)$.

\section{First-line treatment}

Of the 992 cases who had documented KRAS testing, detailed first treatment information was recorded for 678 cases (after excluding 110 cases who reported no chemotherapy; 34 whose chemotherapy status was unknown; 4 cases with discrepancies among treatment variables; and 166 lacking detailed chemotherapy) (Table 3). 
Table 1 Patient characteristics and KRAS testing status among metastatic colorectal cancer diagnosed in 2011.

\begin{tabular}{|c|c|c|c|}
\hline & Tested & Not tested & $P$ \\
\hline Patient characteristic & $N=992(27 \%)$ & $N=2616(73 \%)$ & \\
\hline $\begin{array}{l}\text { Age at diagnosis median } \\
\left(25^{\text {th }}, 75^{\text {th }} \text { percentile) }\right.\end{array}$ & $61(51,69)$ & $64(55,75)$ & $<0.0001$ \\
\hline Age at diagnosis & & & $<0.0001$ \\
\hline$<50$ & $199(36 \%)$ & 347 (64\%) & \\
\hline $50-59$ & $265(31 \%)$ & $582(69 \%)$ & \\
\hline $60-64$ & $163(30 \%)$ & 385 (70\%) & \\
\hline $65-74$ & $216(26 \%)$ & $629(74 \%)$ & \\
\hline$\geq 75$ & $149(18 \%)$ & $673(82 \%)$ & \\
\hline Race/Ethnicity & & & 0.0155 \\
\hline $\begin{array}{l}\text { Non-Hispanic } \\
\text { Whites }\end{array}$ & $688(29 \%)$ & $1681(71 \%)$ & \\
\hline $\begin{array}{l}\text { Non-Hispanic } \\
\text { Blacks }\end{array}$ & 149 (24\%) & $465(76 \%)$ & \\
\hline Hispanic & $155(25 \%)$ & $470(75 \%)$ & \\
\hline Sex & & & 0.5449 \\
\hline Male & $550(28 \%)$ & $1421(72 \%)$ & \\
\hline Female & $442(27 \%)$ & 1195 (73\%) & \\
\hline Residence at diagnosis & & & $<0.0001$ \\
\hline AK & $12(44 \%)$ & $15(56 \%)$ & \\
\hline $\mathrm{CA}^{\mathrm{a}}$ & $35(18 \%)$ & $163(82 \%)$ & \\
\hline $\mathrm{CO}$ & $88(38 \%)$ & $142(62 \%)$ & \\
\hline $\mathrm{FL}^{\mathrm{a}}$ & $160(26 \%)$ & $444(74 \%)$ & \\
\hline ID & $44(36 \%)$ & $78(64 \%)$ & \\
\hline LA & $81(23 \%)$ & $278(77 \%)$ & \\
\hline NC & $211(35 \%)$ & $392(65 \%)$ & \\
\hline $\mathrm{NH}$ & $38(46 \%)$ & $44(54 \%)$ & \\
\hline RI & $24(38 \%)$ & $39(62 \%)$ & \\
\hline TX & $299(23 \%)$ & $1021(77 \%)$ & \\
\hline Census tract povertyb & & & 0.2201 \\
\hline$<20 \%$ & 733 (28\%) & $1886(72 \%)$ & \\
\hline$\geq 20 \%$ & $251(26 \%)$ & $717(74 \%)$ & \\
\hline Insurance statusc & & & 0.0018 \\
\hline No insurance & $99(31 \%)$ & $221(69 \%)$ & \\
\hline Private insurance & $446(31 \%)$ & $999(69 \%)$ & \\
\hline Medicaid & $124(26 \%)$ & $362(74 \%)$ & \\
\hline $\begin{array}{l}\text { Medicare and } \\
\text { other public } \\
\text { insurance }\end{array}$ & $296(25 \%)$ & $900(75 \%)$ & \\
\hline Census tract education ${ }^{\mathrm{d}}$ & & & 0.0023 \\
\hline $\begin{array}{l}<25 \% \text { without a HS } \\
\text { education }\end{array}$ & $773(29 \%)$ & $1916(71 \%)$ & \\
\hline $\begin{array}{l}\geq 25 \% \text { without a HS } \\
\text { education }\end{array}$ & $212(24 \%)$ & $690(76 \%)$ & \\
\hline Census tract Rural/Urbane & & & 0.374 \\
\hline Rural & $84(26 \%)$ & 239 (74\%) & \\
\hline Urban & $544(27 \%)$ & $1486(73 \%)$ & \\
\hline Mixed & $357(29 \%)$ & $881(71 \%)$ & \\
\hline \multicolumn{2}{|c|}{ Number of Charlson Comorbidities } & & 0.1646 \\
\hline 0 comorbid condition & $740(28 \%)$ & 1902 (72\%) & \\
\hline 1 comorbid condition & $195(27 \%)$ & $517(73 \%)$ & \\
\hline $\begin{array}{l}>2 \text { comorbid } \\
\text { condition }\end{array}$ & $57(22 \%)$ & $197(78 \%)$ & \\
\hline
\end{tabular}

Note: ${ }^{a}$ From selected catchment areas; ${ }^{\text {b }}$ Of the 3608 , excluded 21 missing cases; ' Of the 3608 , excluded 161 missing cases; ${ }^{d}$ Of the 3608 , excluded 17 missing cases; ${ }^{e}$ Of the 3608 , excluded 17 missing cases.
Table 2 Multivariate logistic regression of patient characteristics to having a KRAS test among metastatic colorectal patients diagnosed in 2011.

\begin{tabular}{|c|c|c|c|c|}
\hline Characteristic & Value & $O R$ & $95 \% \mathrm{Cl}$ & $P$ \\
\hline \multirow{2}{*}{$\begin{array}{l}\text { Age at diagnosis }{ }^{b} \text { (per } \\
\text { 5-year increase) }\end{array}$} & Below 70 & 0.92 & $(0.88,0.96)$ & $<0.0001$ \\
\hline & Above 70 & 0.76 & $(0.69,0.84)$ & \\
\hline \multirow[t]{3}{*}{ Race/Ethnicity } & $\begin{array}{l}\text { Non- } \\
\text { Hispanic } \\
\text { Whites }\end{array}$ & 1 & & 0.0837 \\
\hline & $\begin{array}{l}\text { Non- } \\
\text { Hispanic } \\
\text { Blacks }\end{array}$ & 0.77 & $(0.61,0.97)$ & \\
\hline & Hispanic & 0.89 & $(0.70,1.12)$ & \\
\hline \multirow[t]{2}{*}{ Sex } & Male & 1 & & 0.8496 \\
\hline & Female & 0.99 & $(0.84,1.15)$ & \\
\hline \multirow[t]{10}{*}{ Residence at diagnosis } & TX & 1 & & $<0.0001$ \\
\hline & AK & 1.68 & $(0.71,3.96)$ & \\
\hline & $C A^{c}$ & 0.7 & $(0.47,1.06)$ & \\
\hline & $\mathrm{CO}$ & 1.98 & $(1.45,2.70)$ & \\
\hline & $\mathrm{FL}^{\mathrm{b}}$ & 1.19 & $(0.93,1.52)$ & \\
\hline & ID & 1.97 & $(1.31,2.97)$ & \\
\hline & LA & 0.93 & $(0.69,1.25)$ & \\
\hline & $\mathrm{NH}$ & 2.98 & $(1.84,4.81)$ & \\
\hline & NC & 1.79 & $(1.42,2.26)$ & \\
\hline & RI & 2.72 & $(1.52,4.85)$ & \\
\hline \multirow[t]{2}{*}{ Census tract poverty } & $<20 \%$ & 1 & & 0.2665 \\
\hline & $\geq 20 \%$ & 1.13 & $(0.91,1.40)$ & \\
\hline \multirow[t]{4}{*}{ Insurance status } & $\begin{array}{l}\text { Private } \\
\text { insurance }\end{array}$ & 1 & & 0.2216 \\
\hline & $\begin{array}{c}\text { No } \\
\text { insurance }\end{array}$ & 1.05 & $(0.80,1.39)$ & \\
\hline & Medicaid & 0.78 & $(0.61,1.01)$ & \\
\hline & $\begin{array}{l}\text { Medicare } \\
\text { \& other } \\
\text { public } \\
\text { insurance }\end{array}$ & 0.97 & $(0.80,1.19)$ & \\
\hline \multirow[t]{2}{*}{ Census tract education } & $\begin{array}{c}<25 \% \\
\text { without HS }\end{array}$ & 1 & & 0.1828 \\
\hline & $\begin{array}{c}\quad \geq 25 \% \\
\text { without HS }\end{array}$ & 0.86 & $(0.69,1.07)$ & \\
\hline \multirow[t]{3}{*}{ Census tract Rural/Urban } & Urban & 1 & & 0.3291 \\
\hline & Mixed & 0.98 & $(0.82,1.18)$ & \\
\hline & Rural & 0.8 & $(0.60,1.08)$ & \\
\hline \multirow{3}{*}{$\begin{array}{l}\text { Number of Charlson } \\
\text { Comorbidities }\end{array}$} & 0 & 1 & & 0.4027 \\
\hline & 1 & 0.97 & $(0.79,1.18)$ & \\
\hline & $>2$ & 0.8 & $(0.58,1.11)$ & \\
\hline
\end{tabular}

Note: a There were 179 missing values excluded from the logistic regression; ${ }^{b}$ Age was transformed in the model using a linear spline function with a knot at Age $=70$. The $p$-value for age is based on the test statistic from the simultaneous test that both age coefficients are equal to 0 ; ${ }^{c}$ From selected catchment areas.

The most common regimens were FOLFOX + bevacizumab (30\%) and FOLFOX alone (17\%), which are both first-line NCCN-recommended treatments at the time [14]. Twenty four cases with a document KRAS test (3\%) received antiEGFR treatment (Table 3). For the 2,616 cases who did not receive a documented KRAS test, detailed first-line treatment information was available for 1,156 cases who 
had no documentation of KRAS testing (Table 3). These cases received similar first-line treatment trend as those who were tested for KRAS. The most common treatments received were FOLFOX + bevacizumab (28\%) or FOLFOX alone (17\%) (Table 3). Thirteen cases (1\%) received antiEGFR treatment even though these cases did not have a documented KRAS test (Table 3).

Table 3 First-line treatment regimens by KRAS testing status among stage IV colorectal patients diagnosed in 2011.

\begin{tabular}{lcc}
\hline & Tested & Not tested \\
\hline Treatment & $\mathrm{N}=678$ & $\mathrm{~N}=1156$ \\
Non anti-EGFR & $561(82.5 \%)$ & $982(84.8 \%)$ \\
FOLFOX alone & $112(16.5 \%)$ & $191(16.5 \%)$ \\
FOLFIRI alone & $13(1.9 \%)$ & $17(1.5 \%)$ \\
CapeOx alone & $22(3.2 \%)$ & $45(3.9 \%)$ \\
FOLFOXIRI alone & $7(1.0 \%)$ & $5(0.4 \%)$ \\
Fluorouacil alone & $32(4.7 \%)$ & $74(6.4 \%)$ \\
Capecitabine alone & $47(6.9 \%)$ & $99(8.6 \%)$ \\
Oxaliplatin alone & $42(6.2 \%)$ & $81(7.0 \%)$ \\
Irinotecan alone & $1(0.1 \%)$ & $1(0.1 \%)$ \\
FOLFOX + bevacizumab & $201(29.6 \%)$ & $325(28.1 \%)$ \\
FOLFIRI + bevacizumab & $30(4.4 \%)$ & $41(3.5 \%)$ \\
CapeOx + bevacizumab & $24(3.5 \%)$ & $50(4.3 \%)$ \\
FOLFOXIRI + bevacizumab & $18(2.7 \%)$ & $14(1.2 \%)$ \\
Fluorouacil + bevacizumab & $4(0.6 \%)$ & $27(2.3 \%)$ \\
Capecitabine + bevacizumab & $8(1.2 \%)$ & $12(1.0 \%)$ \\
Anti-EGFR & $24(3.4 \%)$ & $13(1.2 \%)$ \\
FOLFOX + cetuximab & $13(1.9 \%)$ & $7(0.6 \%)$ \\
FOLFIRI + cetuximab & $3(0.4 \%)$ & $3(0.3 \%)$ \\
FOLFOX + panitumumab & $1(0.1 \%(1.3 \%)$ & $2(0.2 \%)$ \\
\hline Cetuximab alone & & $0.1 \%)$ \\
\hline
\end{tabular}

Overall, of the thirty-seven cases who received anti-EGFR, $65 \%$ had a documented KRAS test while 35\% did not (data not shown). Among those with documentation of both KRAS result and first-line treatment, 354 cases were wildtype and $24(7 \%)$ of these received anti-EGFR treatment; among the 303 cases who had a mutated gene, none $(0 \%)$ received anti-EGFR treatment (Table 4).

Table 4 Receipt of anti-epidermal growth factor receptor (EGFR) monoclonal antibody therapy ${ }^{1}$ among patients with metastatic colorectal cancer with documentation of both KRAS status and treatment result within 12 months of diagnosis in 2011.

\begin{tabular}{lcc}
\hline $\begin{array}{l}\text { Anti-EGFR inhibitor } \\
\text { treatment }^{1}\end{array}$ & Normal (wild-type) & Abnormal (mutated) \\
\hline & $\mathrm{n}=354$ & $\mathrm{n}=303$ \\
Yes & $24(7 \%)$ & $0(0 \%)$ \\
No & $330(93 \%)$ & $303(100 \%)$ \\
\hline
\end{tabular}

Note: ${ }^{1}$ Cetuximab (Erbitux $\left.{ }^{\circledR}\right)$ or Panitumumab (Vectibix ${ }^{\circledR}$ ); ${ }^{2}$ First-line treatment was unknown for 180 normal KRAS cases and 119 abnormal KRAS cases.

\section{Discussion}

CDC'S NPCR collected KRAS testing information and firstline treatment from ten central cancer registries for the first time as part of a registry enhancement project to support Comparative Effectiveness Research. Our findings show that, despite the 2009 NCCN guideline to test all patients with $\mathrm{mCRC}$ for the KRAS mutation, only $27 \%$ of mCRC cases diagnosed in 2011 had a documented KRAS test. Furthermore, among the 534 patients with documented wild-type KRAS mutation for which evidence supports use of anti-EGFR, only 24 (7\%) had documentation of anti-EGFR treatment within the first year of diagnosis. There are several reasons KRAS testing and targeted treatment may be low. One factor may be the delayed integration of NCCN guidelines in clinical practice. Even though recommendations were introduced as early as 2008, lag times from when a recommendation is made to implementation into clinical practice is well known [25, 26]. Also, 2009 KRAS testing guidance from ASCO was more conservative, encouraging testing if anti-EGFR treatment was considered rather than for all patients. Our findings support that clinicians are using FOLFOX + bevacizumab or FOLFOX alone as mCRC first-line treatment, options which do not require a KRAS test.

Disparities in testing and treatment decisions by age, race, or geography may also be a factor influencing the receipt of a KRAS test. First, we observed older patients were less likely to have a documented KRAS test and this was more significant for patients who were 70 years and older. This is probably influenced by older patients having poorer health, more comorbidities, and/or their refusal to therapy or a physician's choice to use another type of treatment [27-30]. Second, in contrast to previous studies, we found a racial disparity in receiving a KRAS test among $\mathrm{mCRC}$ cancer patients [31, 32]. Our findings indicate that the odds of receiving a KRAS test are $23 \%$ lower for nonHispanic Blacks than for non-Hispanic Whites. Wallace et al. demonstrated that Blacks were less likely than Whites to receive a physician's recommendation for CRC screening [31]. Blacks are also more likely to have advanced CRC but less likely to be informed about CRC guidelines when compared to Whites [32]. Blacks are overall less likely to be treated with chemotherapy and since KRAS testing is closely tied to treatment, it is possible they are receiving less KRAS testing because of this [32]. Finally, our findings also suggest a geographic disparity in receiving a KRAS test with half of the central cancer registries: Colorado, Idaho, New Hampshire, North Carolina, and Rhode Island reporting more testing than the southern states of Texas, Florida, and Louisiana as well as California. Geographic differences may be explained by practice variations among the states in our study; however, future research is needed to really understand if there are other factors impacting this difference. Even though insurance status was not a significant predictor of KRAS testing when controlling for other factors, our study suggests that those who had Medicaid and Medicare and other public insurance had less KRAS testing than those who had no insurance. This is a surprising finding as we expected those who had no insurance to have lesS KRAS testing due to cost; however, insurance status is collected at initial diagnosis and/or 
treatment not at the end of treatment. Harlan et al. study found that patients who had Medicare and Medicaid were less likely to receive guideline cancer care compared to patients who had no insurance, private, or other insurance [33]. Overall, patient-level insurance status and census tract-level socioeconomic variables did not influence a person's KRAS testing status as suspected. After adjusting for covariates, lower census tract education did not remain a predictor of receiving a KRAS test.

A strength in our study is that we utilized the NPCR cancer registry system to collect and estimate KRAS testing. Our CER project covered approximately $27 \%$ of the US population and included diverse populations, representing approximately $25 \%$ of African Americans and $44 \%$ of Hispanics living in the United States for 2011 diagnosis year [19]. We believe that NPCR registries were able to adequately capture KRAS testing because our results align with results from an analysis of 2010 Surveillance, Epidemiology, and End Results (SEER) data by Charlton et al. that found $23 \%$ of $\mathrm{mCRC}$ cases were tested for KRAS, thus corroborating overall low use of KRAS testing in the United States [34]. Other studies have assessed KRAS uptake in other countries and the United States that have found higher KRAS utilization were not population-based and either used clinical trial data or integrated healthcare data, which can offer many limitations. Webster et al. found that $36 \%$ of patients in an integrated healthcare setting in the United States received KRAS testing [35]. Ciardiello et al. looked at KRAS utilization in Europe, Latin America, and Asia and saw an increase of 3\% in 2008 to $69 \%$ in 2010 [36]. In Webster et al. findings, patients with more comorbidities were associated with less KRAS testing; however, our study did not find the number of Charlson comorbidities to impact a person's KRAS testing status.

More significantly, our study is the first to collect detailed first-line treatment agents, including anti-EGFR, for mCRC on a population level by KRAS status. We found that antiEGFR is given sparingly as first-line treatment including among those with a documented normal KRAS. However, no one in our study received anti-EGFR treatment who was tested and had a mutated gene. The low use of antiEGFR treatment was also seen in Abrams et al. study, given to only $4 \%$ of their US-wide mCRC cohort [37]. Our data showed that FOLFOX + bevacizumab was the most common first-line chemotherapy treatment given to both tested and not tested groups. The second most common treatment was FOLFOX among both groups. Both of these treatments do not require a KRAS test. According to NCCN guidelines, there are several chemotherapy first-line regimens a physician can chose to prescribe a patient, other than anti-EGFR treatment, that are equally efficient based on NCCN recommendations and would not require a KRAS test. Moreover, another underlying factor potentially influencing physicians to use anti-EGFR treatment so sparingly is that it is substantially more expensive than other available treatments [7]; however, cost was not evaluated in this study.

Despite CDC's NPCR standardized cancer collection system and abstractors who were trained on coding for nonNAACCR variables, there may have been limitations related to capturing KRAS testing. This was the first time KRAS biomarker data were collected and there may have been abstractors who missed KRAS testing information from a patient's medical chart or the test results were not found in the medical chart. Pathology reports are not standardized; therefore, this makes it harder for abstractors to find the required information at physicians' offices, which can be very labor intensive and subject to human error. Also, KRAS tests are sometimes sent to outside laboratories and results take time to be entered into. Results could have been missed if they were entered after the abstraction period. Data were only collected up to 12 months postdiagnosis. Therefore, it was not possible to further analyze the treatment data. If data collection had lasted longer, it is possible KRAS testing utilization could have increased if a patient's first-line treatment failed. Another limitation which may account for why our study did not find comorbidities to impact a person's KRAS testing status; those who had no documented comorbidities could include those patients with unknown comorbidities. Lastly, while cost of KRAS testing and anti-EGFR therapy may influence the decision of KRAS testing, we did not collect such information.

\section{Conclusion}

This is the first population-based study that assessed both $K R A S$ testing and detailed first-line treatment information. Our findings help understand KRAS testing in the diagnosis year 2011, which to our knowledge is the latest populationbased data on KRAS testing. The limited use of KRAS testing and use of anti-EGFR treatment reflects the slow adoption and incorporation of biomarkers in cancer care, despite guidance from professional organizations. The application of biomarkers is expanding in the diagnosis and treatment of solid tumors. Thus, there is a need to validate the capture of these factors in cancer surveillance systems as well as conduct longitudinal studies to examine testing and treatment beyond the first year of diagnosis, including the impact on cancer recurrence and death. The findings of our study, however, demonstrated that capacity of cancer registries to assess KRAS to document the uptake of KRAS testing in the United States and provide the foundation to study the impact of KRAS on treatment decisions and patient-centered outcomes.

\section{Acknowledgments}

We would like to acknowledge the project investigators at the participating central cancer registries, as well as other organizations, and individuals, including the registrars, that supported the collection of the data to enhance NPCR for Comparative Effectiveness Research: Alaska Cancer Registry (Judy Brockhouse); Cancer Registry of Greater California (Dee W. West); Colorado Central Cancer Registry (Randi K. Rycroft); Cancer Data Registry of Idaho (Christopher J. Johnson); Florida Cancer Data System (Monique N. Hernandez); Division of Cancer Prevention and Control, National Center for Chronic Disease Prevention and Health Promotion, Centers for Disease Control and Prevention (Christie R. Eheman, David Butterworth); ICF International (Kevin B. Zhang) Louisiana Tumor Registry and Epidemiology Program; Rhode Island Cancer Registry (David Rousseau); New Hampshire State 
Cancer Registry (Maria O. Celaya); CDC-NPCR Contractor, DB Consulting (Jennifer M. Wike); North Carolina Cancer Registry (Melissa Pearson); and Texas Cancer Registry (Anne M. Hakenewerth).

\section{Funding}

This work was supported in part under CDC Cooperative Agreements of the National Program of Cancer Registries: \#U58/DP000792 in conjunction with the participating states and a CDC Comparative Effectiveness Research contract to ICF: \#200-2008-27957.

\section{Disclaimer}

The findings and conclusions in this report are those of the authors and do not necessarily represent the official position of the Centers for Disease Control and Prevention.

\section{References}

[1] US Cancer Statistics Working Group. United States Cancer Statistics: 1999-2013 Incidence and Mortality Web-based Report. 2016 ed. Atlanta, GA: US Department of Health and Human Services, Centers for Disease Control and Prevention and National Cancer Institute. 2016.

[2] Howlader N, Noone AM, Krapcho M, Miller D, Bishop K, et al. SEER Cancer Statistics Review, 1975-2013, National Cancer Institute. Bethesda, MD, based on November 2015 SEER data submission, 2016. http://seer.cancer.gov/csr/1975_2013/

[3] Fleming M, Ravula S, Tatishchev SF, Wang HL. Colorectal carcinoma: Pathologic aspects. J Gastrointest Oncol. 2012; 3(3):153-73.

[4] Ploquin A, Zerimech F, Escande F, Adenis A, Giraud C, et al. Lack of relationship between clinical features and KRAS mutations in patients with metastatic colorectal cancer. Anticancer Res. 2016; 36(8):42334236.

[5] Rose JS, Serna DS, Martin LK, Li X, Weatherby LM, et al. Influence of KRAS mutation status in metachronous and synchronous metastatic colorectal adenocarcinoma. Cancer. 2012; 118(24):6243-6252.

[6] Sinicrope FA, Okamoto K, Kasi PM, Kawakami H. Molecular biomarkers in the personalized treatment of colorectal cancer. Clin Gastroenterol Hepatol. 2016; 14(5):651-658.

[7] Behl AS, Goddard KA, Flottemesch TJ, Veenstra D, Meenan RT, et al. Cost-effectiveness analysis of screening for KRAS and BRAF mutations in metastatic colorectal cancer. J Natl Cancer Inst. 2012; 104(23):17851795.

[8] Ross JS, Torres-Mora J, Wagle N, Jennings TA, Jones DM. Biomarkerbased prediction of response to therapy for colorectal cancer: Current perspective. Am J Clin Pathol. 2010; 134(3):478-490.

[9] Heinemann V, von Weikersthal LF, Decker T, Kiani A, Vehling-Kaiser $U$, et al. FOLFIRI plus cetuximab versus FOLFIRI plus bevacizumab as first-line treatment for patients with metastatic colorectal cancer (FIRE-3): A randomised, open-label, phase 3 trial. Lancet Oncol. 2014; 15(10):1065-1075.

[10] Van Cutsem E, Lenz HJ, Kohne CH, Heinemann V, Tejpar S, et al. Fluorouracil, leucovorin, and irinotecan plus cetuximab treatment and RAS mutations in colorectal cancer. J Clin Oncol. 2015; 33(7):692-700.

[11] Engstrom PF, Arnoletti JP, Benson AB, Chen Y], Choti MA, et al. NCCN clinical practice guidelines in oncology: Colon cancer. J Nat Compr Canc Netw. 2009; 7(8):778-831.

[12] Allegra CJ, Jessup JM, Somerfield MR, Hamilton SR, Hammond EH, et al. American Society of Clinical Oncology provisional clinical opinion: Testing for KRAS gene mutations in patients with metastatic colorectal carcinoma to predict response to anti-epidermal growth factor receptor monoclonal antibody therapy. J Clin Oncol. 2009; 27(12):2091-2096.

[13] U.S. Food and Drug Administration. FDA Approves Cetuximab (Erbitux) and Panitumumab (Vectibix). 2009.

[14] NCCN clinical practice guidelines in oncology for colon cancer. 2011.

[15] Karthaus M, Hofheinz RD, Mineur L, Letocha H, Greil R, et al. Impact of tumour RAS/BRAF status in a first-line study of panitumumab + FOLFIRI in patients with metastatic colorectal cancer. Br J Cancer. 2016; 115(10):1215-1222.
[16] Lupini L, Bassi C, Mlcochova J, Musa G, Russo M, et al. Prediction of response to anti-EGFR antibody-based therapies by multigene sequencing in colorectal cancer patients. BMC cancer. 2015; 15:808.

[17] Ohhara Y, Fukuda N, Takeuchi S, Honma R, Shimizu Y, et al. Role of targeted therapy in metastatic colorectal cancer. World J Gastrointest Oncol. 2016; 8(9):642-655.

[18] NCCN clinical practice guidelines in oncology: Colon cancer. 2017. Fort Washington, PA.

[19] Chen VW, Eheman CR, Johnson CJ, Hernandez MN, Rousseau D, et al. Enhancing Cancer Registry Data for Comparative Effectiveness Research (CER) Project: Overview and methodology. J Registry Manag. 2014; 41(3):103-112.

[20] Surveillance, Epidemiology, and End Results (SEER) Program. National Cancer Institute.

[21] American Community Survey 5-Year Estimates; generated using American FactFinder. 2010.

[22] Quan H, Sundararajan V, Halfon P, Fong A, Burnand B, et al. Coding algorithms for defining comorbidities in ICD-9-CM and ICD-10 administrative data. Med Care. 2005; 43(11):1130-1139.

[23] Charlson ME, Pompei P, Ales KL, MacKenzie CR. A new method of classifying prognostic comorbidity in longitudinal studies: Development and validation. J Chronic Dis. 1987; 40(5):373-383.

[24] Harrell FE. Regression Modeling Strategies: With Applications to linear models, logistic regression, and survival analysis. New York: Springer; 2011.

[25] Green LW. Making research relevant: If it is an evidence-based practice, where's the practice-based evidence? Fam Pract. 2008; 25 Suppl 1:i20-4.

[26] Westfall JM, Mold J, Fagnan L. Practice-based research--"Blue Highways" on the NIH roadmap. JAMA. 2007; 297(4):403-406.

[27] Asch SM, Kerr EA, Keesey J, Adams JL, Setodji CM, et al. Who is at greatest risk for receiving poor-quality health care? N Engl J Med. 2006; 354(11):1147-1156.

[28] Bouchardy C, Rapiti E, Blagojevic S, Vlastos AT, Vlastos G. Older female cancer patients: Importance, causes, and consequences of undertreatment. J Clin Oncol. 2007; 25(14):1858-1869.

[29] Elkin EB, Kim SH, Casper ES, Kissane DW, Schrag D. Desire for information and involvement in treatment decisions: elderly cancer patients' preferences and their physicians' perceptions. J Clin Oncol. 2007; 25(33):5275-5280.

[30] Koroukian SM, Murray P, Madigan E. Comorbidity, disability, and geriatric syndromes in elderly cancer patients receiving home health care. J Clin Oncol. 2006; 24(15):2304-2310.

[31] Coleman Wallace DA, Baltrus PT, Wallace TC, Blumenthal DS, Rust GS. Black white disparities in receiving a physician recommendation for colorectal cancer screening and reasons for not undergoing screening. J Health Care Poor Underserved. 2013; 24(3):1115-1124.

[32] Dimou A, Syrigos KN, Saif MW. Disparities in colorectal cancer in African-Americans vs Whites: before and after diagnosis. World J Gastroenterol. 2009; 15(30):3734-3743.

[33] Harlan LC, Greene AL, Clegg LX, Mooney M, Stevens JL, et al. Insurance status and the use of guideline therapy in the treatment of selected cancers. J Clin Oncol. 2005; 23(36):9079-9088.

[34] Charlton ME, Karlitz JJ, Schlichting JA, Chen VW, Lynch CF. Factors associated with guideline-recommended KRAS testing in colorectal cancer patients. Am J Clin Oncol. 2015.

[35] Webster J, Kauffman TL, Feigelson HS, Pawloski PA, Onitilo AA, et al. KRAS testing and epidermal growth factor receptor inhibitor treatment for colorectal cancer in community settings. Cancer Epidemiol Biomarkers Prev. 2013; 22(1):91-101.

[36] Ciardiello F, Tejpar S, Normanno N, Mercadante D, Teague T, et al. Uptake of KRAS mutation testing in patients with metastatic colorectal cancer in Europe, Latin America and Asia. Target Oncol. 2011; 6(3):133145.

[37] Abrams TA, Meyer G, Schrag D, Meyerhardt JA, Moloney J, et al. Chemotherapy usage patterns in a US-wide cohort of patients with metastatic colorectal cancer. Journal of the National Cancer Institute 2014; 106(2):1-10. 